Supporting Information for:

\title{
Detection of Amines and Unprotected Amino Acids in Aqueous Conditions by Formation of Highly Fluorescent Iminium Ions
}

\author{
Ellen K. Feuster and Timothy E. Glass* \\ Department of Chemistry, The Pennsylvania State University, University Park, PA 16802
}

\section{Titration methods}

For UV/Vis and fluorescence assays, a $10^{-5} \mathrm{M}$ solution of the sensor was prepared in buffer solution (100 mM NaCl, $50 \mathrm{mM}$ HEPES, adjusted to $\mathrm{pH}=7.4)$. This solution was placed in a cuvette (1 $\mathrm{ml}$ for $\mathrm{UV} / \mathrm{Vis}$ and $2.5 \mathrm{ml}$ for fluorescence) and the temperature adjusted to $37^{\circ} \mathrm{C}$. The sample was then titrated with a solution of amino acid ( $1 \mathrm{M}$ in $100 \mathrm{mM} \mathrm{NaCl}, 50 \mathrm{mM}$ HEPES, adjusted to $\mathrm{pH}=7.4$ with $10^{-5} \mathrm{M}$ sensor to prevent dilution). The change in absorbance or fluorescence was fit to a typical equilibrium model (see below) ${ }^{1}$ to derive an equilibrium constant $\left(\mathrm{K}_{\mathrm{eq}}=1 / \mathrm{m} 2\right)$. The maximum change in fluorescence was calculated from the theoretical fit at complete saturation $\left(\mathrm{I}_{\max } / \mathrm{I}_{0}=\mathrm{m} 1+1\right)$.
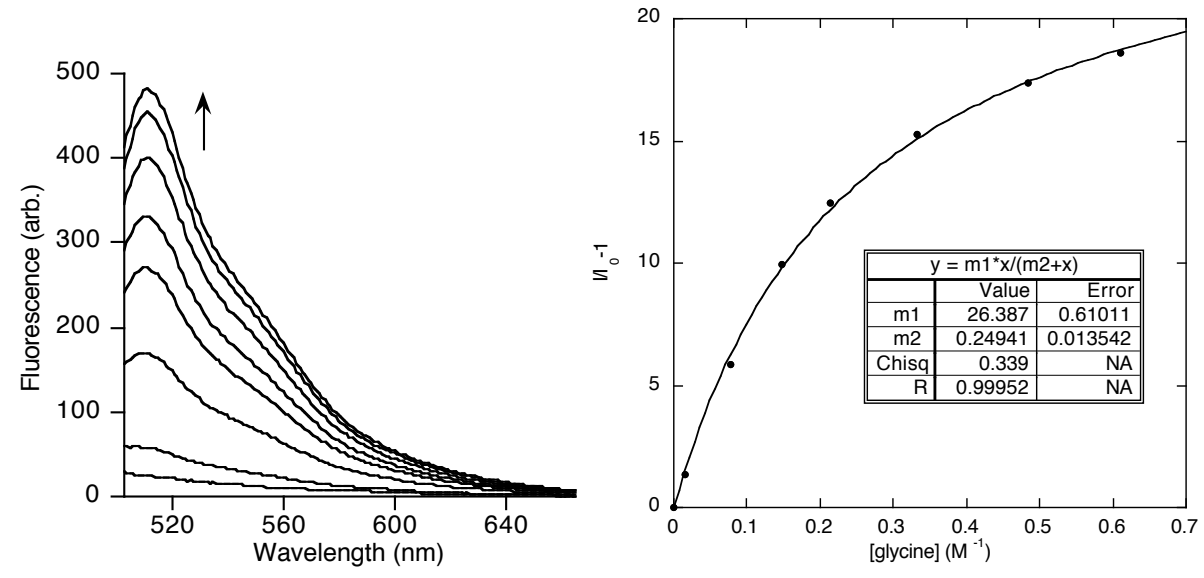

NMR titrations were performed in $\mathrm{D}_{2} \mathrm{O}$ with no buffer or $\mathrm{NaCl}$. For compound 3,10 mg of aldehyde was dissolved in $\mathrm{D}_{2} \mathrm{O}(1 \mathrm{ml})$ with a small amount of $\mathrm{NaHCO}_{3}$. To this sample was added 100 $\mathrm{mg}$ of $\mathrm{d}_{5}$-glycine. The subsequent NMR consisted of the aldehyde and imine only. The ratio of aldehyde and imine signals along with the known concentration of glycine were used to calculate a $\mathrm{K}_{\mathrm{eq}}$ $=0.47 \mathrm{M}^{-1}$. For compound $4,4 \mathrm{mg}$ of aldehyde was dissolved in $\mathrm{D}_{2} \mathrm{O}(1 \mathrm{ml})$ with a small amount of $\mathrm{DCl}$ such that the $\mathrm{pD}=7.0$. To this sample was added $100 \mathrm{mg}$ of $\mathrm{d}_{5}$-glycine. The subsequent NMR consisted of the aldehyde and imine only. The ratio of aldehyde and imine signals along with the known concentration of glycine were used to calculate a $\mathrm{K}_{\mathrm{eq}}=0.29 \mathrm{M}^{-1}$. 


\section{$\underline{\text { Synthetic Procedures }}$}

\section{Compound 1b:}

A suspension of $\mathrm{CuI}(0.3 \mathrm{~g}, 1.8 \mathrm{mmol})$ and $\mathrm{Et}_{2} \mathrm{O}(15 \mathrm{~mL})$ was cooled to $0^{\circ} \mathrm{C}$ and $\mathrm{n}-\mathrm{BuLi}(1.7 \mathrm{~mL}, 3.4$ mmol, $2 \mathrm{M}$ in pentane) was slowly added. After $20 \mathrm{~min}$, the resultant blue solution was cooled to $-78^{\circ} \mathrm{C}$ and THF $(15 \mathrm{~mL})$ was added. 4-Chloro-7-diethylamino-3-formylcoumarin ${ }^{2}$ (0.5 g, $\left.1.8 \mathrm{mmol}\right)$ in THF $(8 \mathrm{~mL})$ was added dropwise over $10 \mathrm{~min}$. The reaction was stirred at $-78^{\circ} \mathrm{C}$ for $10 \mathrm{~min}$ and then quenched with saturated $\mathrm{NH}_{4} \mathrm{Cl}$. The aqueous layer was extracted with $\mathrm{CH}_{2} \mathrm{Cl}_{2}(3 \mathrm{x} 50 \mathrm{~mL})$. The organic layer was then dried over $\mathrm{MgSO}_{4}$ and the solvent was removed in vacuo. Flash chromatography (EtOAc/Hex, 20:80) gave compound $\mathbf{1 b}$ as an orange solid (0.4 g, 78\% yield), M.P. $69-72^{\circ} \mathrm{C}$.

${ }^{1} \mathbf{H}$ NMR (400 MHz, $\left.\mathrm{CDCl}_{3}\right) ; \square 0.99$ (t, $\left.J=7.0 \mathrm{~Hz}, 3 \mathrm{H}\right), 1.24(\mathrm{t}, J=7.1 \mathrm{~Hz}, 6 \mathrm{H}), 1.49-1.60$ (m, 4H), $3.26(\mathrm{t}, J=7.9 \mathrm{~Hz}, 2 \mathrm{H}), 3.46(\mathrm{q}, J=7.1 \mathrm{~Hz}, 4 \mathrm{H}), 6.48(\mathrm{~d}, J=2.6 \mathrm{~Hz}, 1 \mathrm{H}), 6.65(\mathrm{dd}, J=2.6,9.3 \mathrm{~Hz}$, 1H), $7.62(\mathrm{~d}, J=9.3 \mathrm{~Hz}, 1 \mathrm{H}), 10.37(\mathrm{~s}, 1 \mathrm{H})$.

${ }^{13}$ C NMR (75 MHz, $\left.\mathrm{CDCl}_{3}\right)$; $\square$ 12.5, 13.8, 23.3, 27.5, 32.6, 45.0, 97.3, 108.5, 109.8, 111.7, 128.5, $152.5,157.5,163.2,164.1,164.2,190.8$.

FTIR (neat) 1708, 1672, 1608, 1555, 1502, 1443, 1349, 1267, 1202, 1149, $1114 \mathrm{~cm}^{-1}$.

HRMS Calculated for $\mathrm{C}_{18} \mathrm{H}_{24} \mathrm{NO}_{3}\left(\mathrm{M}+\mathrm{H}^{+}\right)$: 302.1756. Found: 302.1751 .

\section{Compound 4:}
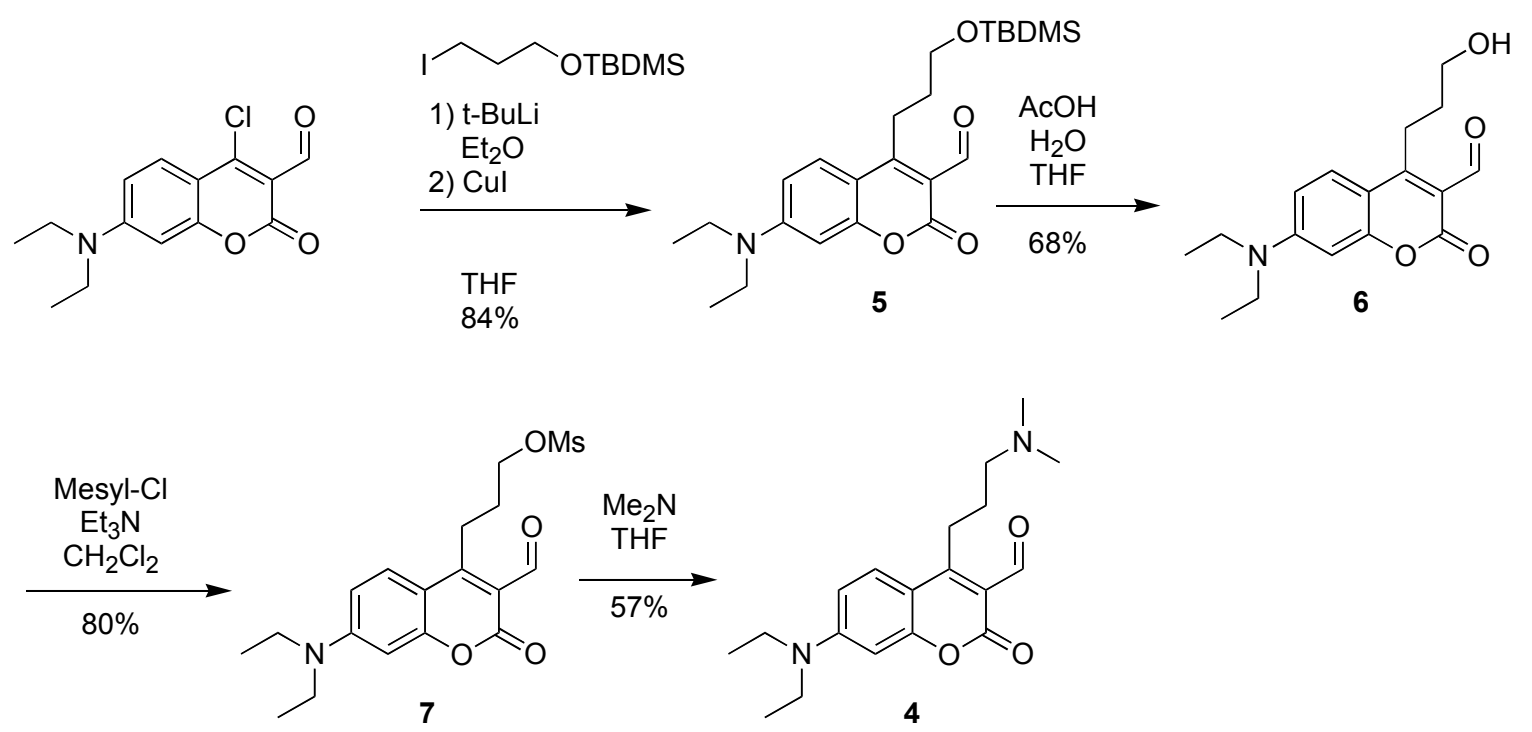
(tert-Butyl-dimethylsilyl)-3-iodo-propanol ${ }^{3}(0.4 \mathrm{~g}, 1.4 \mathrm{mmol})$ and $\mathrm{Et}_{2} \mathrm{O}(15 \mathrm{~mL})$ were cooled to $-78^{\circ} \mathrm{C}$ and tert-BuLi (1.8 mL, $3.0 \mathrm{mmol}, 1.6 \mathrm{M}$ in pentane) was slowly added. The mixture was stirred at $-78^{\circ} \mathrm{C}$ for $5 \mathrm{~min}$ then warmed to ambient temperature and stirred $1 \mathrm{~h}$. After cooling to $0^{\circ} \mathrm{C}, \mathrm{CuI}(0.14$ g, $0.7 \mathrm{mmol})$ was added and stirred $10 \mathrm{~min}$. The reaction was cooled to $-78^{\circ} \mathrm{C}$ and $\mathrm{THF}$ was added $(8$ $\mathrm{mL})$. 4-Chloro-7-diethylamino-3-formylcoumarin $(0.2 \mathrm{~g}, 1.4 \mathrm{mmol})$ in THF $(6 \mathrm{~mL})$ was added dropwise over 10 mins. The reaction was stirred $0.5 \mathrm{~h}$ at $-78^{\circ} \mathrm{C}$ and then quenched with saturated $\mathrm{NH}_{4} \mathrm{Cl}$. The aqueous layer was extracted with $\mathrm{CH}_{2} \mathrm{Cl}_{2}(3 \times 50 \mathrm{~mL})$. The organic layer was then dried over $\mathrm{MgSO}_{4}$ and the solvent was removed in vacuo. Flash chromatography (EtOAc/Hex, 20:80) gave compound 5 as an orange solid $(0.2 \mathrm{~g}, 73 \%$ yield $)$, M.P. $98-100^{\circ} \mathrm{C}$.

${ }^{1} \mathbf{H}$ NMR $\left(360 \mathrm{MHz}, \mathrm{CDCl}_{3}\right) \square 0.10(\mathrm{~s}, 6 \mathrm{H}), 0.95$ (s, 9H), 1.25 (t, J=6.9 Hz, 6H), 1.79-1.84 (m, 2H), 3.31-3.36 (m, 2H), 3.46 (q, $J=7.1 \mathrm{~Hz}, 4 \mathrm{H}), 3.77$ (t, $J=5.9 \mathrm{~Hz}, 2 \mathrm{H}), 6.45$ (d, $J=2.6 \mathrm{~Hz}, 1 \mathrm{H}), 6.61$ (dd, $J=2.6,9.3 \mathrm{~Hz}, 1 \mathrm{H}), 7.75(\mathrm{~d}, J=9.3 \mathrm{~Hz}, 1 \mathrm{H}), 10.34(\mathrm{~s}, 1 \mathrm{H})$.

${ }^{13}$ C NMR (75 MHz, $\left.\mathrm{CDCl}_{3}\right) \square-5.3,12.5,18.3,24.5,25.9,33.2,45.0,62.7,97.2,108.6,109.8,111.8$, $129.0,152.6,157.5,163.1,164.0,190.8$.

FTIR (neat) 2928, 1788, 1678, 1615, 1561, 1510, 1458, 1355, 1269, 1204, 1148, $1098 \mathrm{~cm}^{-1}$.

HRMS Calculated for $\mathrm{C}_{23} \mathrm{H}_{36} \mathrm{NO}_{4} \mathrm{Si}\left(\mathrm{M}+\mathrm{H}^{+}\right)$: 418.2414. Found: 418.2408.

Compound 5 (0.2 g, $0.5 \mathrm{mmol})$ was dissolved in a solution of $\mathrm{AcOH}: \mathrm{H}_{2} \mathrm{O}$ : THF (3:1:1) and stirred at ambient temperature for $4 \mathrm{~h}$. The reaction was carefully poured over saturated $\mathrm{NaHCO}_{3}$ and the aqueous layer was extracted with $\mathrm{CH}_{2} \mathrm{Cl}_{2}(3 \times 15 \mathrm{~mL})$. The organic layer was dried over $\mathrm{MgSO}_{4}$ and the solvent was removed in vacuo. The resulting residue was purified via flash chromatography (EtOAc/Hex, 50:50) and compound 6 was isolated as an orange solid (0.9 g, 62\% yield), M.P. 122$125^{\circ} \mathrm{C}$.

${ }^{1} \mathbf{H}$ NMR $\left(300 \mathrm{MHz}, \mathrm{CDCl}_{3}\right) \square 1.25(\mathrm{t}, J=7.1 \mathrm{~Hz}, 6 \mathrm{H}), 1.85-1.94(\mathrm{~m}, 2 \mathrm{H}), 3.37(\mathrm{t}, J=7.6 \mathrm{~Hz}, 2 \mathrm{H})$, $3.46(\mathrm{q}, J=7.1 \mathrm{~Hz}, 4 \mathrm{H}), 3.74(\mathrm{t}, J=5.6 \mathrm{~Hz}, 2 \mathrm{H}), 6.45(\mathrm{~d}, J=2.4 \mathrm{~Hz}, 1 \mathrm{H}), 6.66(\mathrm{dd}, J=2.4,9.3 \mathrm{~Hz}$, 1H), $7.69(\mathrm{~d}, J=9.3 \mathrm{~Hz}, 1 \mathrm{H}), 10.34(\mathrm{~s}, 1 \mathrm{H})$.

${ }^{13}$ C NMR (75 MHz, $\left.\mathrm{CDCl}_{3}\right) \square$ 12.4, 24.0, 33.1, 45.1, 61.6, 97.2, 108.4, 110.0, 111.9, 128.8, 152.8, 157.6, 163.0, 163.4, 191.6.

FTIR (neat) 3396, 2913, 1706, 1670, 1610, 1552, 1503, 1453, 1347, 1267, 1150 , $1069 \mathrm{~cm}^{-1}$.

HRMS Calculated for $\mathrm{C}_{17} \mathrm{H}_{22} \mathrm{NO}_{4}\left(\mathrm{M}+\mathrm{H}^{+}\right)$: 304.1549. Found: 304.1543. 
A solution of compound $6(70 \mathrm{mg}, 0.2 \mathrm{mmol}), \mathrm{Et}_{3} \mathrm{~N}(40 \square \mathrm{L}, 0.3 \mathrm{mmol})$, and $\mathrm{CH}_{2} \mathrm{Cl}_{2}(3 \mathrm{~mL})$ was stirred at $0^{\circ} \mathrm{C}$. Methanesulfonyl chloride $(20 \square \mathrm{L}, 0.3 \mathrm{mmol})$ was added and the reaction was stirred at $0^{\circ} \mathrm{C}$ for 10 mins. The solvent was removed in vacuo and the resulting residue was purified using flash chromatography (EtOAc/Hex, 30:70) and compound 7 was isolated as a yellow solid (73 $\mathrm{mg}, 83 \%$ yield), M.P. $126-128^{\circ} \mathrm{C}$.

${ }^{1}$ H NMR $\left(300 \mathrm{MHz}, \mathrm{CDCl}_{3}\right) \square 1.23(\mathrm{t}, J=7.1 \mathrm{~Hz}, 6 \mathrm{H}), 2.01-2.10(\mathrm{~m}, 2 \mathrm{H}), 3.08(\mathrm{~s}, 3 \mathrm{H}), 3.30-3.39(\mathrm{~m}$, $2 \mathrm{H}), 3.46(\mathrm{q}, J=7.1 \mathrm{~Hz}, 4 \mathrm{H}), 4.42(\mathrm{t}, J=5.9 \mathrm{~Hz}, 2 \mathrm{H}), 6.50(\mathrm{sd}, J=2.6 \mathrm{~Hz}, 1 \mathrm{H}), 6.68(\mathrm{dd}, J=2.6,9.3$ $\mathrm{Hz}, 1 \mathrm{H}), 7.65$ (d, $J=9.4 \mathrm{~Hz}, 1 \mathrm{H}), 10.34$ (s, 1H).

${ }^{13}$ C NMR (75 MHz, $\left.\mathrm{CDCl}_{3}\right) \square$ 12.9, 24.6, 30.1, 37.9, 45.6, 70.5, 97.8, 108.7, 110.7, 112.1, 129.0, $153.4,158.1,162.0,163.4,191.4$.

FTIR (neat) 2975, 1712, 1673, 1613, 1556, 1506, 1454, 1352, $1172 \mathrm{~cm}^{-1}$.

HRMS Calculated for $\mathrm{C}_{18} \mathrm{H}_{24} \mathrm{NO}_{6} \mathrm{~S}\left(\mathrm{M}+\mathrm{H}^{+}\right)$: 382.1324. Found: 382.1319 .

In a $15 \mathrm{~mL}$ sealed tube, compound $7(61 \mathrm{mg}, 0.2 \mathrm{mmol})$ and $\mathrm{Me}_{2} \mathrm{NH}(5 \mathrm{~mL}, 2 \mathrm{M}$ in THF) were capped and stirred at ambient temperature for $20 \mathrm{~h}$. The solvent was removed in vacuo. The resulting residue was purified using flash chromatography $\left(\mathrm{EtOAc} / \mathrm{Et}_{3} \mathrm{~N}, 90: 10\right)$ and compound $\mathbf{4}$ was isolated as an orange solid (32 mg, 57\% yield), M.P. $119-121^{\circ} \mathrm{C}$.

${ }^{1}$ H NMR $\left(300 \mathrm{MHz}, \mathrm{CDCl}_{3}\right) \square 1.25(\mathrm{t}, J=7.1 \mathrm{~Hz}, 6 \mathrm{H}), 1.73(\mathrm{~m}, 2 \mathrm{H}), 2.27(\mathrm{~s}, 6 \mathrm{H}), 2.46(\mathrm{t}, J=7.1 \mathrm{~Hz}$, 2H), $3.29(\mathrm{~m}, 2 \mathrm{H}), 3.46$ (q, $J=7.1 \mathrm{~Hz}, 4 \mathrm{H}), 6.45(\mathrm{~d}, J=2.6 \mathrm{~Hz}, 1 \mathrm{H}), 6.64(\mathrm{dd}, J=2.6,9.3 \mathrm{~Hz}, 1 \mathrm{H})$, $7.70(\mathrm{~d}, J=9.3 \mathrm{~Hz}, 1 \mathrm{H}), 10.36(\mathrm{~s}, 1 \mathrm{H})$.

${ }^{13}$ C NMR $\left(75 \mathrm{MHz}, \mathrm{CDCl}_{3}\right) \square$ 12.5, 25.7, 28.2, 45.0, 45.4, 59.4, 97.2, 108.6, 109.8, 111.7, 128.7, $152.6,157.5,163.1,163.8,190.8$.

FTIR (neat) 2972, 1716, 1674, 1615, 1558, 1506, 1456, 1354, 1142, $1075 \mathrm{~cm}^{-1}$.

HRMS Calculated for $\mathrm{C}_{19} \mathrm{H}_{27} \mathrm{~N}_{2} \mathrm{O}_{3}\left(\mathrm{M}+\mathrm{H}^{+}\right)$: 331.2022. Found: 331.2016. 


\section{Compound 3:}
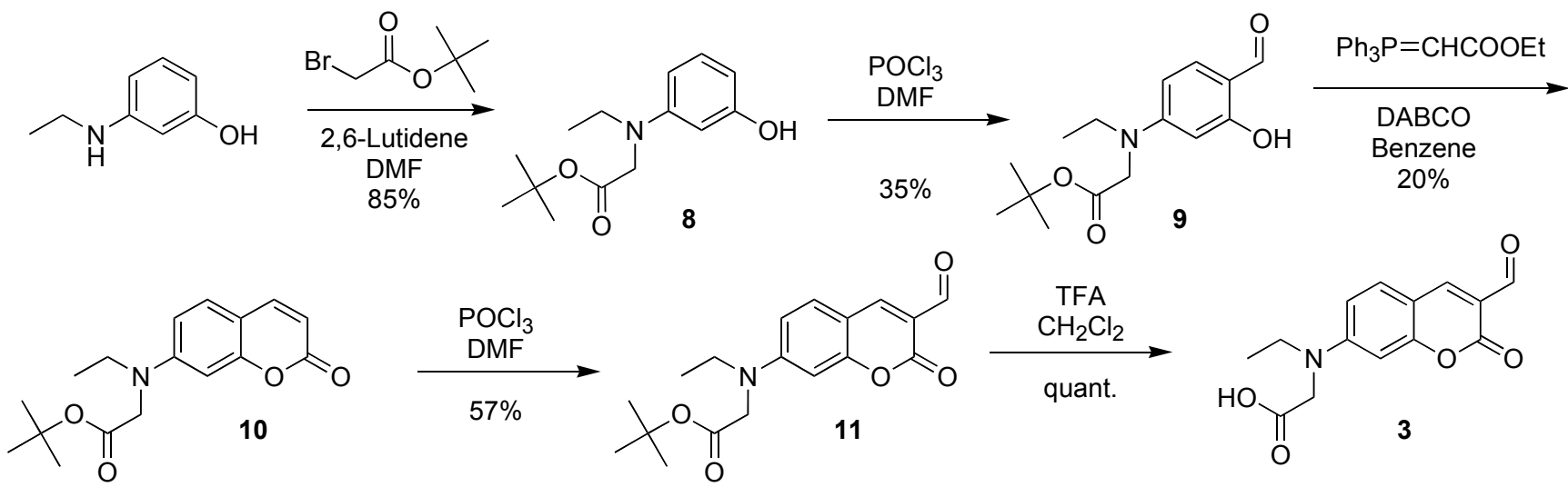

A solution of 3-(ethylamino)phenol $(1.0 \mathrm{~g}, 5.6 \mathrm{mmol}), 2,6$-lutidene $(5 \mathrm{~mL})$, tert-butyl bromoacetate (1.0 mL, $6.4 \mathrm{mmol})$, and DMF (40 mL) was stirred at ambient temperature for $20 \mathrm{~h}$. The solvent was removed in vacuo and the resulting residue was purified using flash chromatography $\left(\mathrm{CH}_{2} \mathrm{Cl}_{2} / \mathrm{Et}_{2} \mathrm{O}\right.$, 95:5). Compound 8 was isolated as a brown oil ( $0.7 \mathrm{~g}, 50 \%$ yield $)$.

${ }^{1}$ H NMR $\left(300 \mathrm{MHz}, \mathrm{CDCl}_{3}\right) \square 1.15(\mathrm{t}, J=7.1 \mathrm{~Hz}, 3 \mathrm{H}), 1.43(\mathrm{~s}, 9 \mathrm{H}), 3.39$ (q, $\left.J=7.1 \mathrm{~Hz}, 2 \mathrm{H}\right) 3.87$ (s, 2H), $6.04(\mathrm{~s}, 1 \mathrm{H}), 6.12-6.18(\mathrm{~m}, 3 \mathrm{H}), 7.00(\mathrm{t}, J=8.0 \mathrm{~Hz}, 1 \mathrm{H})$.

${ }^{13} \mathbf{C}$ NMR $\left(75 \mathrm{MHz}, \mathrm{CDCl}_{3}\right) \square 12.4,28.0,46.1,53.2,81.8,99.2,103.9,104.4,129.9,149.3,156.8$, 171.2.

FTIR (neat) 3403, 1725, 1620, 1582, 1504, 1369, 1219, 1156, $1127 \mathrm{~cm}^{-1}$.

HRMS Calculated for $\mathrm{C}_{14} \mathrm{H}_{22} \mathrm{NO}_{3}\left(\mathrm{M}+\mathrm{H}^{+}\right)$: 252.1600. Found: 252.1594 .

A solution of DMF $(0.5 \mathrm{~mL}, 6.8 \mathrm{mmol})$ and phosphorous oxychloride $(0.3 \mathrm{~mL}, 2.7 \mathrm{mmol})$ were stirred at ambient temperature for $2 \mathrm{~h}$. Compound $8(0.7 \mathrm{~g}, 2.7 \mathrm{mmol})$ in DMF (15 ml) was added via cannula. The reaction was stirred at ambient temperature for $20 \mathrm{~h}$. The mixture was slowly poured over ice, and the aqueous layer was extracted with $\mathrm{CH}_{2} \mathrm{Cl}_{2}(3 \times 50 \mathrm{~mL})$. The organic layer was dried over $\mathrm{MgSO}_{4}$ and the solvent was removed in vacuo. The resulting residue was purified by flash chromatography (EtOAc/Hex, 20:80) and compound 9 was isolated as a white solid (0.6 g, 73\% yield), M.P. 77-79 ${ }^{\circ}$.

${ }^{1}$ H NMR (360 MHz, $\left.\mathrm{CDCl}_{3}\right) \square 1.30(\mathrm{t}, J=7.2 \mathrm{~Hz}, 3 \mathrm{H}), 1.46(\mathrm{~s}, 9 \mathrm{H}), 3.49$ (q, $\left.J=7.2 \mathrm{~Hz}, 2 \mathrm{H}\right), 3.97$ (s, 2H), $6.05(\mathrm{~d}, J=2.3 \mathrm{~Hz}, 1 \mathrm{H}), 6.21(\mathrm{dd}, J=2.3,8.8 \mathrm{~Hz}, 1 \mathrm{H}), 7.28(\mathrm{~d}, J=8.8 \mathrm{~Hz}, 1 \mathrm{H}), 9.53(\mathrm{~s}, 1 \mathrm{H})$, $11.55(\mathrm{~s}, 1 \mathrm{H})$.

${ }^{13}$ C NMR $\left(75 \mathrm{MHz}, \mathrm{CDCl}_{3}\right) \square$ 12.2, 27.8, 46.6, 52.8, 82.1, 97.3, 104.4, 112.0, 135.2, 154.5, 164.0, 168.6, 192.4 . 
FTIR (neat) 2978, 1741, 1635, 1561, 1523, 1340, 1233, $1152 \mathrm{~cm}^{-1}$.

HRMS Calculated for $\mathrm{C}_{15} \mathrm{H}_{22} \mathrm{NO}_{4}\left(\mathrm{M}+\mathrm{H}^{+}\right)$: 280.1549. Found: 280.1543.

A solution of compound $9(0.5 \mathrm{~g}, 1.9 \mathrm{mmol})$, DABCO $(0.4 \mathrm{~g}, 3.7 \mathrm{mmol})$, (carbethoxymethylene)triphenylphosphorane $(0.8 \mathrm{~g}, 2.2 \mathrm{mmol})$ and benzene $(20 \mathrm{~mL})$ was heated to a vigorous reflux for $20 \mathrm{~h}$. The solution was cooled to ambient temperature and poured into $1 \% \mathrm{HCl}(30 \mathrm{~mL})$. The aqueous layer was extracted with $\mathrm{CH}_{2} \mathrm{Cl}_{2}(3 \times 20 \mathrm{~mL})$. The organic layer was dried over $\mathrm{MgSO}_{4}$ and the solvent was removed in vacuo. The resulting residue was purified by flash chromatography (EtOAc/Hex, 15:85) and compound 10 was isolated as an amorphous white solid (120 mg, 20\% yield).

${ }^{1} \mathbf{H}$ NMR $\left(300 \mathrm{MHz}, \mathrm{CD}_{2} \mathrm{Cl}_{2}\right) \square 1.22(\mathrm{t}, J=7.2 \mathrm{~Hz}, 3 \mathrm{H}), 1.45(\mathrm{~s}, 9 \mathrm{H}), 3.50(\mathrm{q}, J=7.2 \mathrm{~Hz}, 2 \mathrm{H}), 3.98(\mathrm{~s}$, $2 \mathrm{H}), 6.00(\mathrm{~d}, J=9.4 \mathrm{~Hz}, 1 \mathrm{H}), 6.44(\mathrm{~d}, J=2.4 \mathrm{~Hz}, 1 \mathrm{H}), 6.53(\mathrm{dd}, J=2.5,8.8 \mathrm{~Hz}, 1 \mathrm{H}), 7.28(\mathrm{~d}, J=8.8$ $\mathrm{Hz}, 1 \mathrm{H}), 7.55(\mathrm{~d}, J=9.4 \mathrm{~Hz}, 1 \mathrm{H})$.

${ }^{13}$ C NMR (75 MHz, $\left.\mathrm{CD}_{2} \mathrm{Cl}_{2}\right) \square$ 12.4, 28.1, 47.1, 53.3, 82.3, 98.3, 109.1, 109.5, 110.4, 129.1, 143.9, $151.4,156.8,161.9,169.4$.

FTIR (neat) 1732, 1615, 1520, 1415, 1224, 1154, $1121 \mathrm{~cm}^{-1}$.

HRMS Calculated for $\mathrm{C}_{17} \mathrm{H}_{22} \mathrm{NO}_{4}\left(\mathrm{M}+\mathrm{H}^{+}\right)$: 304.1549. Found: 304.1543 .

A solution of DMF ( $0.2 \mathrm{~mL}, 2.6 \mathrm{mmol})$ and phosphorous oxychloride $(0.1 \mathrm{~mL}, 1.1 \mathrm{mmol})$ were stirred at ambient temperature for $2 \mathrm{~h}$. Compound $10(65 \mathrm{mg}, 0.2 \mathrm{mmol})$ in DMF (2 ml) was added via cannula. The reaction was stirred at ambient temperature for $20 \mathrm{~h}$. The mixture was slowly poured over ice, and the aqueous layer was extracted with $\mathrm{CH}_{2} \mathrm{Cl}_{2}(3 \times 20 \mathrm{~mL})$. The organic layer was dried over $\mathrm{MgSO}_{4}$ and the solvent was removed in vacuo. The resulting residue was purified via flash chromatography (EtOAc/Hex, 10:90) and compound 11 was isolated as a yellow solid (40 $\mathrm{mg}, 57 \%$ yield), M.P. $124-126^{\circ} \mathrm{C}$.

${ }^{1} \mathbf{H}$ NMR $\left(300 \mathrm{MHz}, \mathrm{CDCl}_{3}\right) \square 1.29(\mathrm{t}, J=7.2 \mathrm{~Hz}, 3 \mathrm{H}), 1.48(\mathrm{~s}, 9 \mathrm{H}), 3.56(\mathrm{q}, J=7.2 \mathrm{~Hz}, 2 \mathrm{H}), 4.04(\mathrm{~s}$, 2H), $6.45(\mathrm{~d}, J=2.4 \mathrm{~Hz}, 1 \mathrm{H}), 6.61(\mathrm{dd}, J=2.4,9.0 \mathrm{~Hz}, 1 \mathrm{H}), 7.45$ (d, $J=9.0 \mathrm{~Hz}, 1 \mathrm{H}), 8.27(\mathrm{~s}, 1 \mathrm{H})$, $10.13(\mathrm{~s}, 1 \mathrm{H})$.

${ }^{13}$ C NMR $\left(75 \mathrm{MHz}, \mathrm{CDCl}_{3}\right) \square 12.1,27.9,47.2,53.1,82.8,97.7,108.9,110.2,115.2,132.3,145.5$, $153.8,158.5,161.5,168.1,187.8$.

FTIR (neat) 2977, 1720, 1683, 1618, 1576, 1510, 1393, 1349, 1155, $1123 \mathrm{~cm}^{-1}$.

HRMS Calculated for $\mathrm{C}_{18} \mathrm{H}_{22} \mathrm{NO}_{5}\left(\mathrm{M}+\mathrm{H}^{+}\right)$: 332.1498. Found: 332. 1492. 
Compound 11 (11.3 mg, $0.03 \mathrm{mmol})$, trifluoroacetic acid $(1 \mathrm{~mL})$, and $\mathrm{CH}_{2} \mathrm{Cl}_{2}(1 \mathrm{~mL})$ were stirred at ambient temperature for $1.5 \mathrm{~h}$. The solvent was removed in vacuo to afford compound $\mathbf{3}$, a yellow solid ( $8.3 \mathrm{mg}, 100 \%$ yield), M.P. $180^{\circ} \mathrm{C}$ (decomp.).

${ }^{1} \mathrm{H}$ NMR (300 MHz, $\mathrm{D}_{2} \mathrm{O}$ with NaOD) $\square 0.99(\mathrm{t}, J=7.1 \mathrm{~Hz}, 3 \mathrm{H}), 3.22$ (q, $\left.J=7.0 \mathrm{~Hz}, 2 \mathrm{H}\right), 5.66(\mathrm{~d}, J=$ $2.5 \mathrm{~Hz}, 1 \mathrm{H}), 5.91$ (dd, $J=2.4,9.2 \mathrm{~Hz}, 1 \mathrm{H}), 7.34$ (d, $J=9.2 \mathrm{~Hz}, 1 \mathrm{H}), 7.51$ (s, 1H), 8.78 (s br, 1H).

${ }^{13}$ C NMR (75 MHz, $d_{6}$-DMSO) $\square$ 12.0, 46.3, 51.6, 97.0, 108.2, 110.6, 114.1, 132.8, 146.4, 154.1, 158.0, 160.5, 170.8, 187.3.

FTIR (neat) 2925, 1717, 1682, 1616, 1575, 1510, 1394, 1348, $1186 \mathrm{~cm}^{-1}$.

HRMS Calculated for $\mathrm{C}_{14} \mathrm{H}_{13} \mathrm{NO}_{5}\left(\mathrm{M}+\mathrm{H}^{+}\right)$: 276.0870. Found: 276.0873 .

1. Connors, K. A. Binding Constants; John Wiley; New York, 1987.

2. (a) Kirpichenok, M. A.; Baukulev, V. M.; Karandashova, L. A.; Grandberg, I. I. Chem. Heterocycl. Compd. 1991, 27, 1193-1199. (b) Knierzinger, A.; Wolfbeis, O. S. J. Heterocyclic Chem. 1980, 17, 225-229.

3. Nicolaou, K. C.; Papahatjis, D. P.; Claremon, D. A.; Dolle, R. E., III J. Am. Chem. Soc. 1981, 103, 6967-6969. 

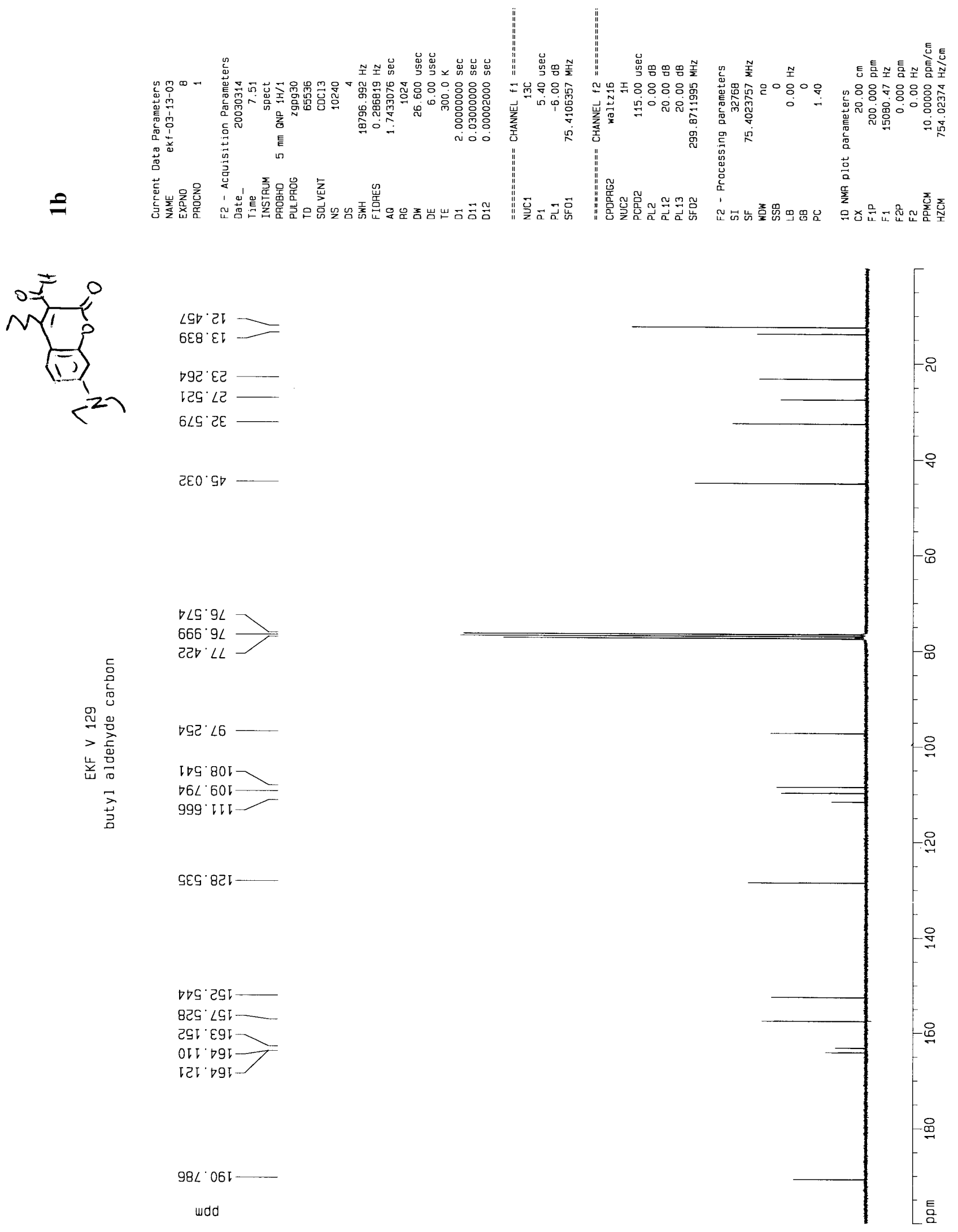

$\nabla \nabla G^{\circ} 295$

8टद $\angle 95$

टG ' $E 9$

०レ๐ \

饵จ9上

$98 \angle 061$

wdd 

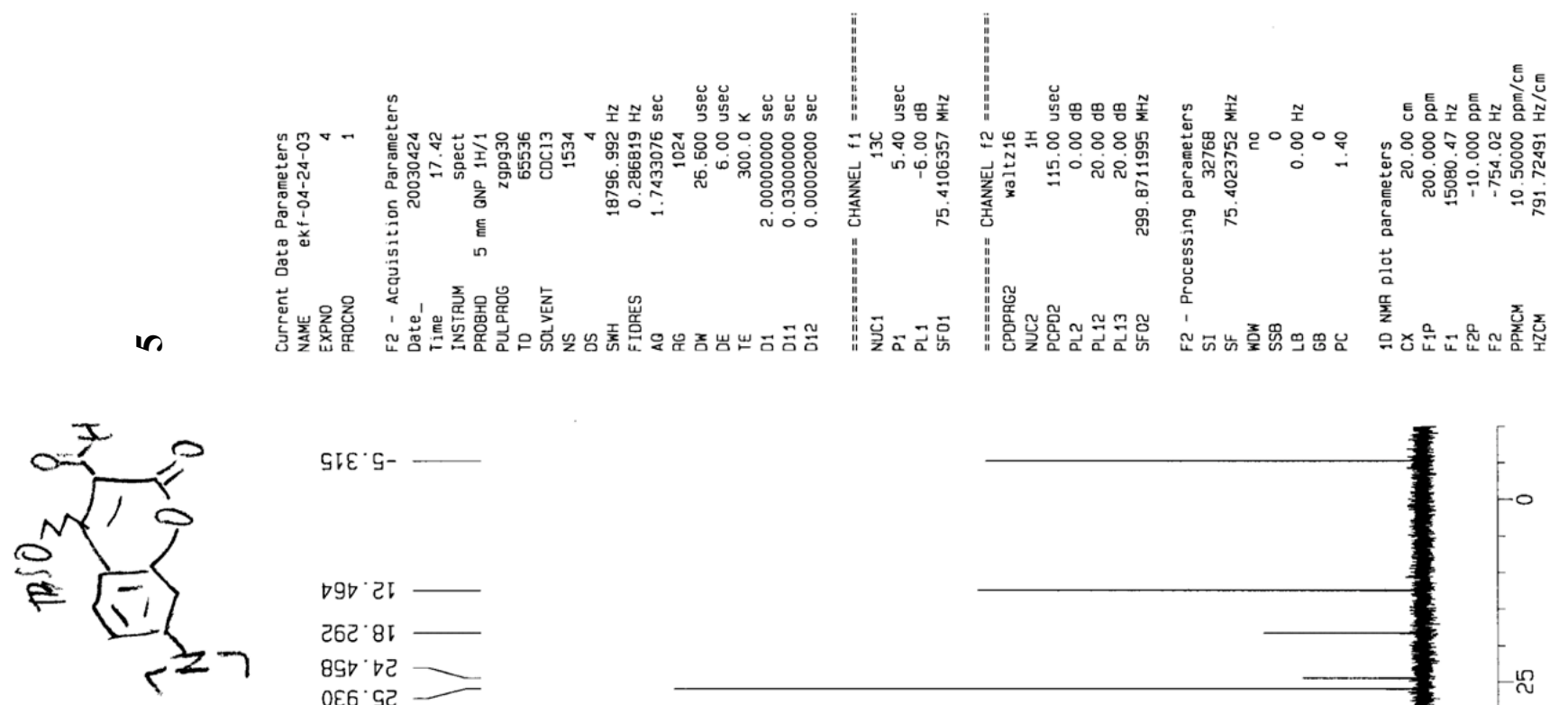

૬โย. ร-

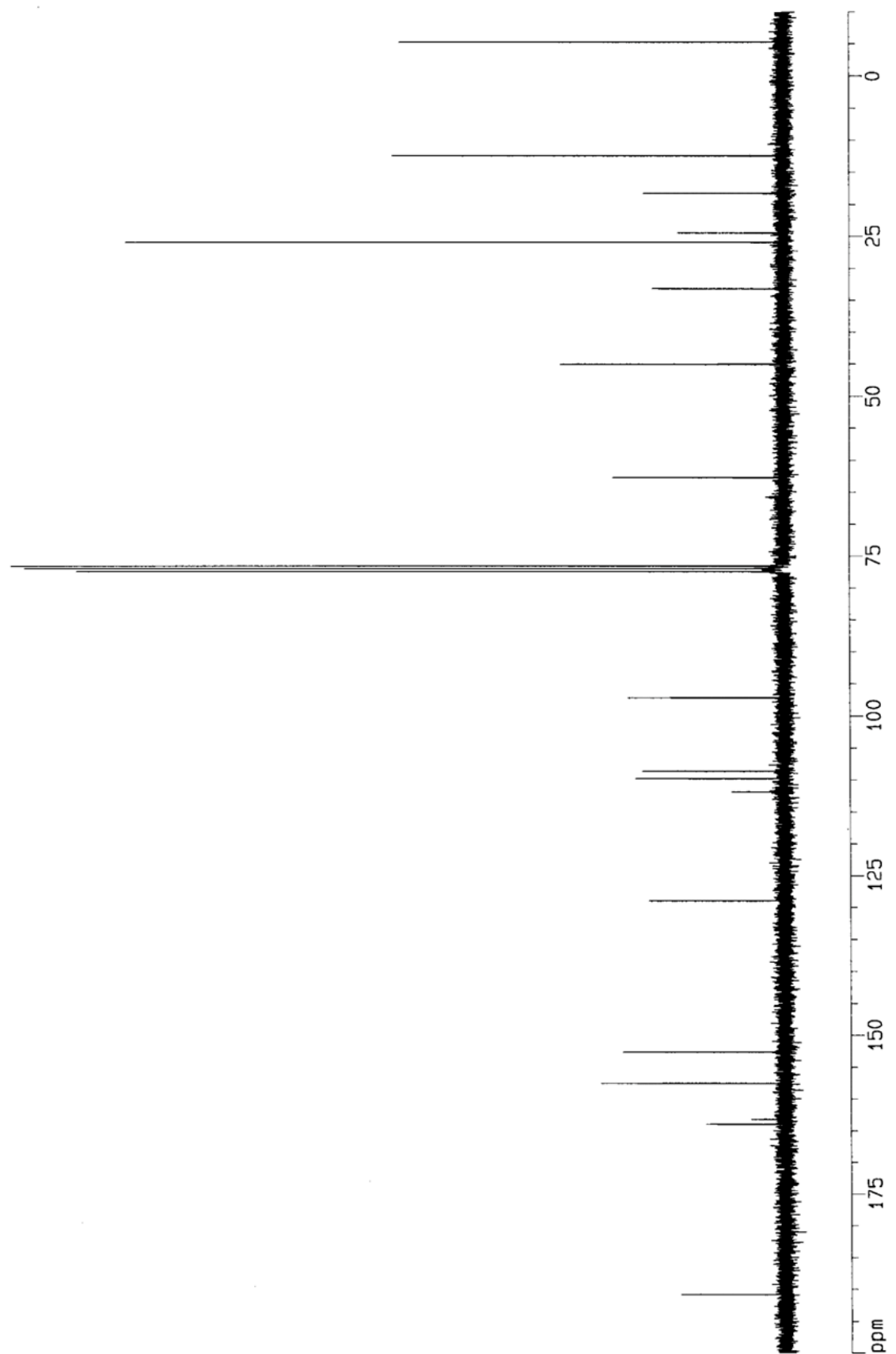

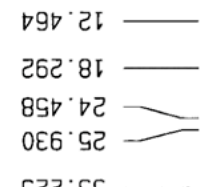

૬टટ $\varepsilon$

GEO '

$069^{\circ} 29 \div$

$\nabla \angle G^{\circ} 9 \angle$

$866^{\circ} 9 L$

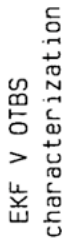

ICD $\angle L$

$\varepsilon 8 I^{\circ} \angle 6$

OD9.801
$29 \angle .601$
D28.

ع96.8टा - 

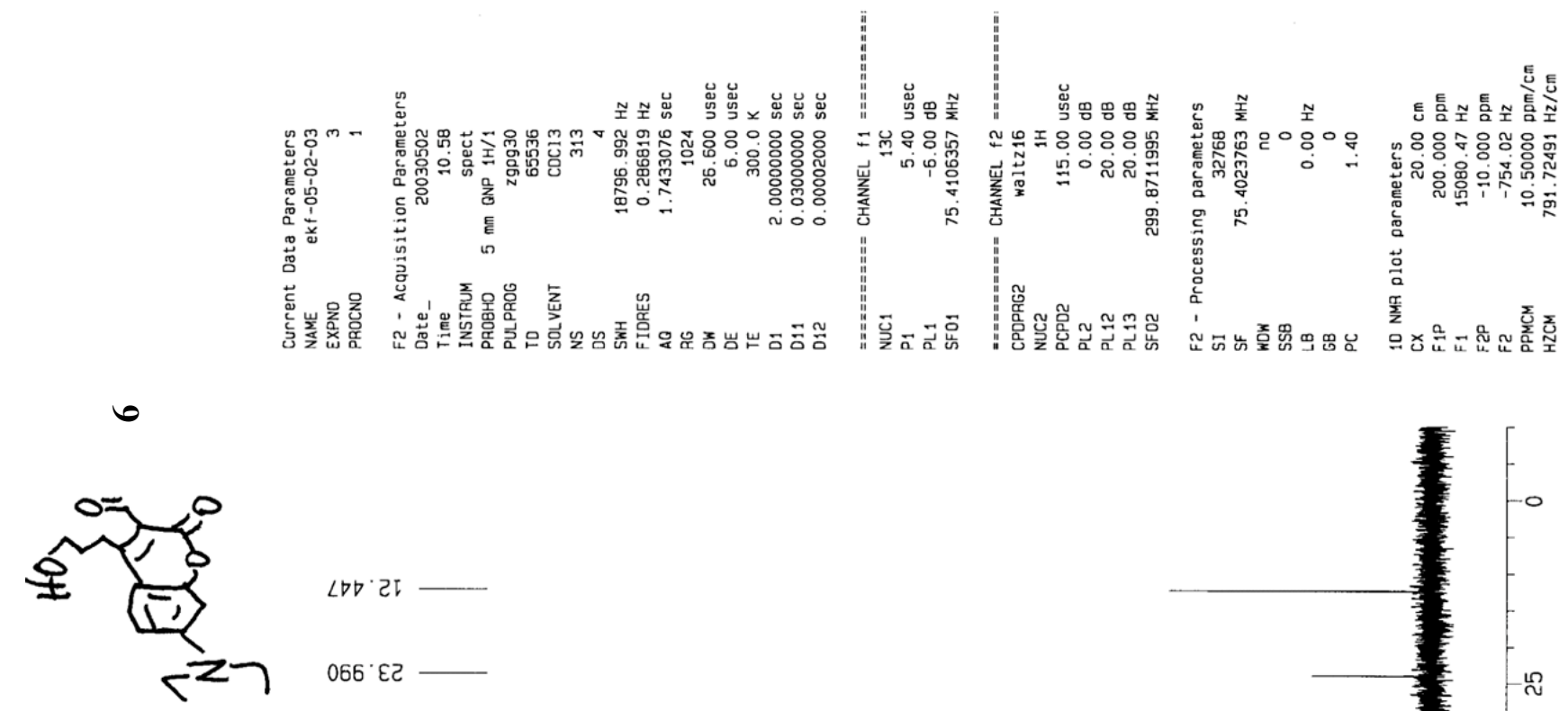

$\angle \Delta \nabla^{\circ} 2$

$066^{\circ} \varepsilon 己$

૦น દE

$980^{\circ} \mathrm{Gb}$

org't9 -

$\mathrm{S} \angle \mathrm{G}^{\circ} \mathrm{g} \angle$

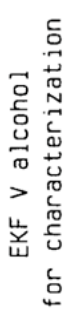

$000^{\circ} \angle L D$

Iट2 $\angle 6$

$86 \varepsilon^{\circ} 801-$
$\nabla 20.01-$

208.821
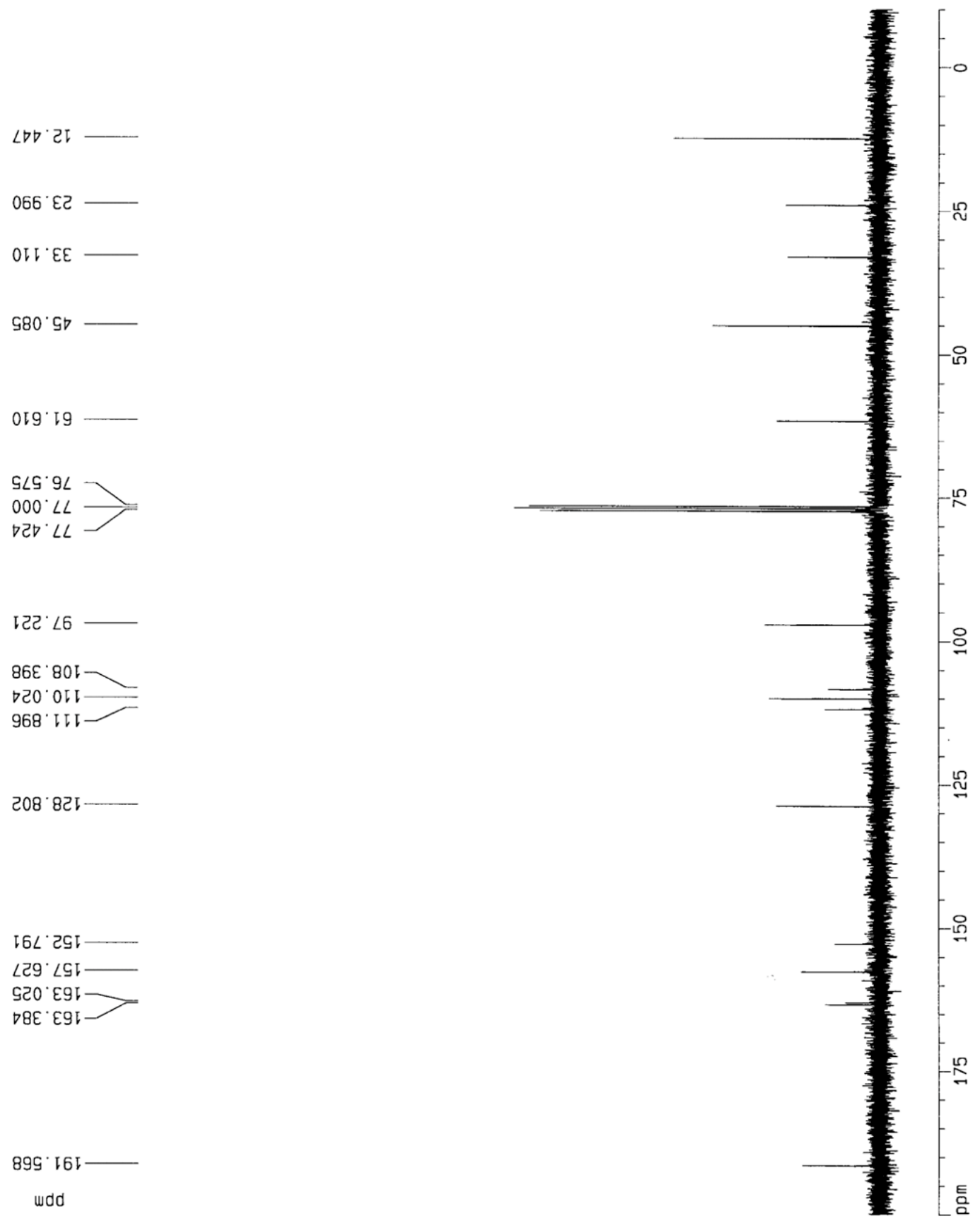

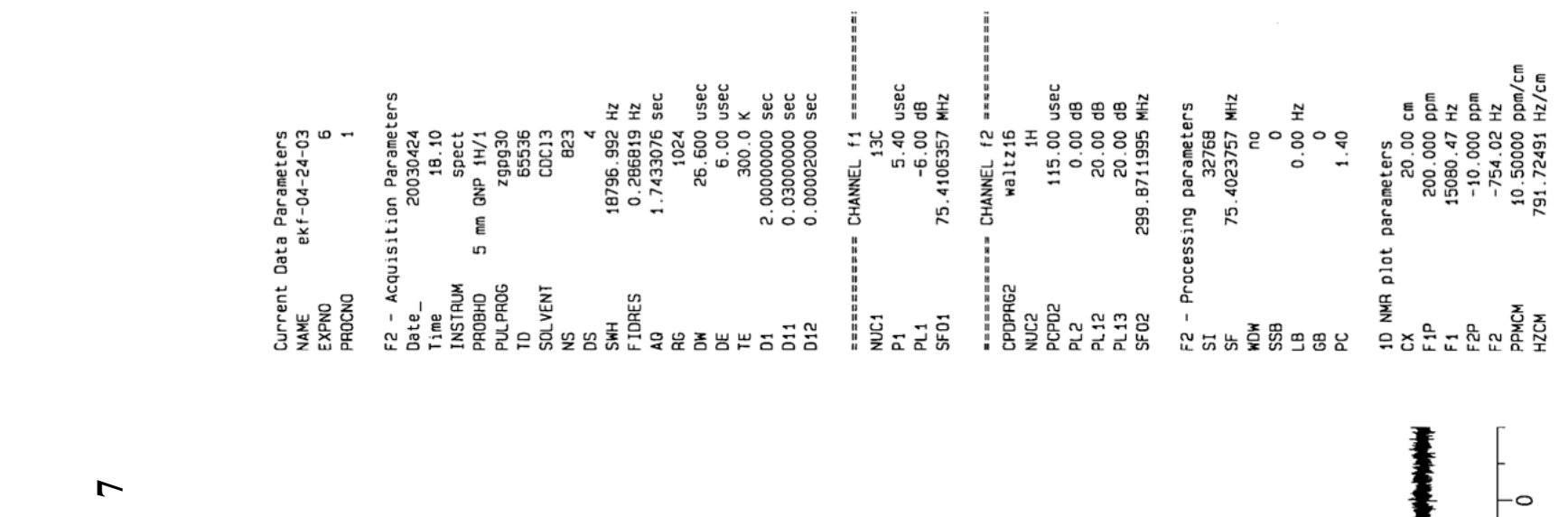

-
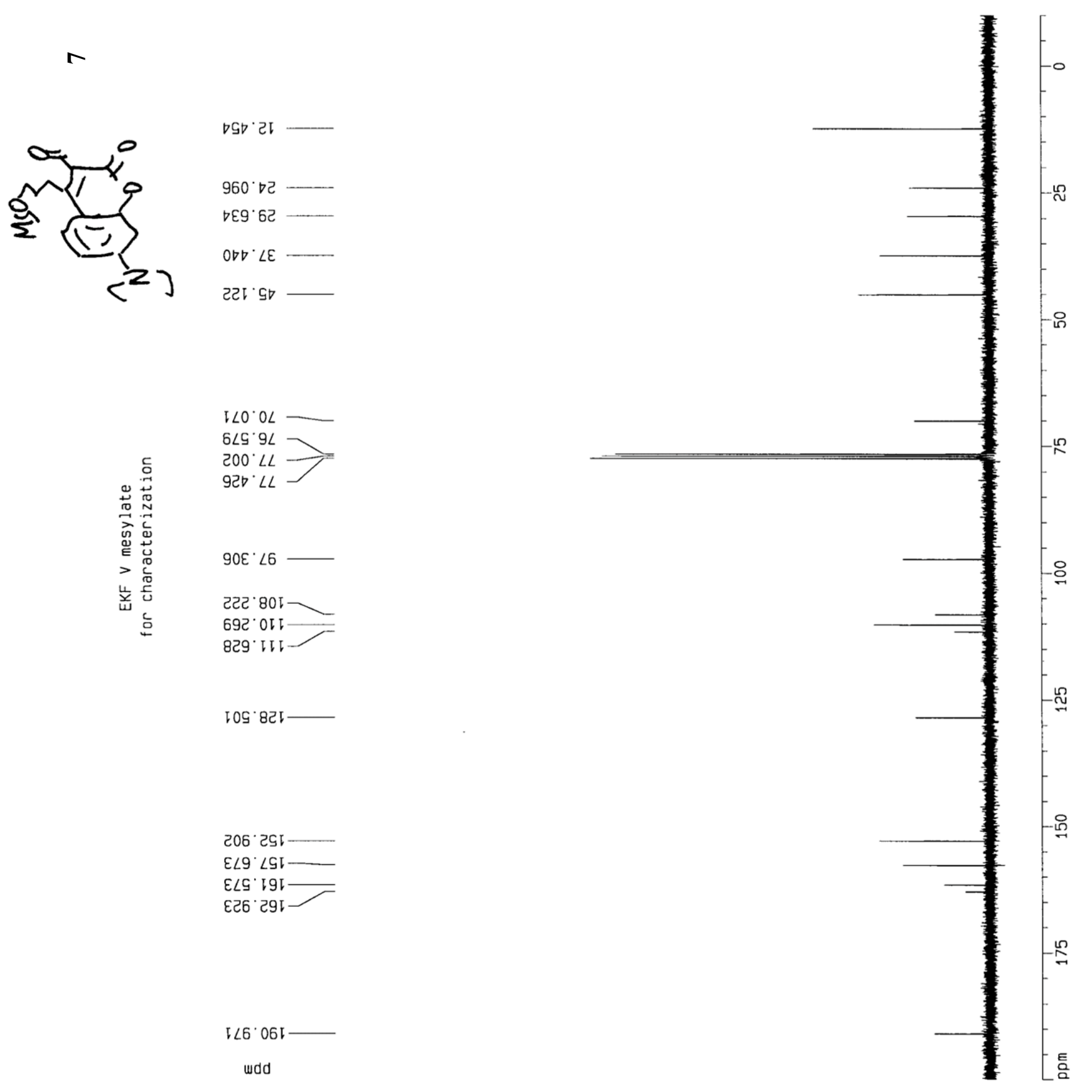

$\operatorname{Lg} 821$

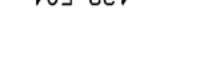

wdd 


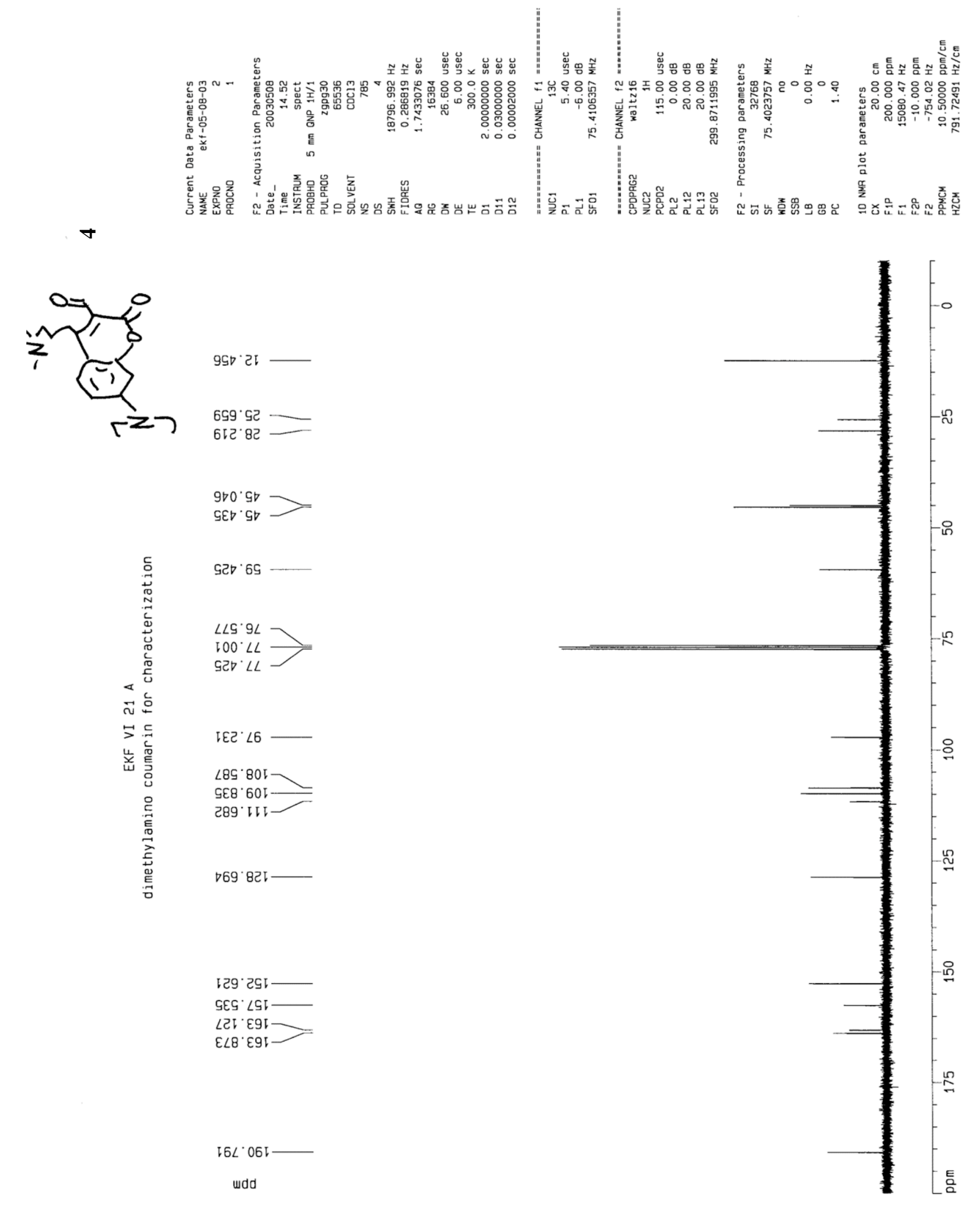




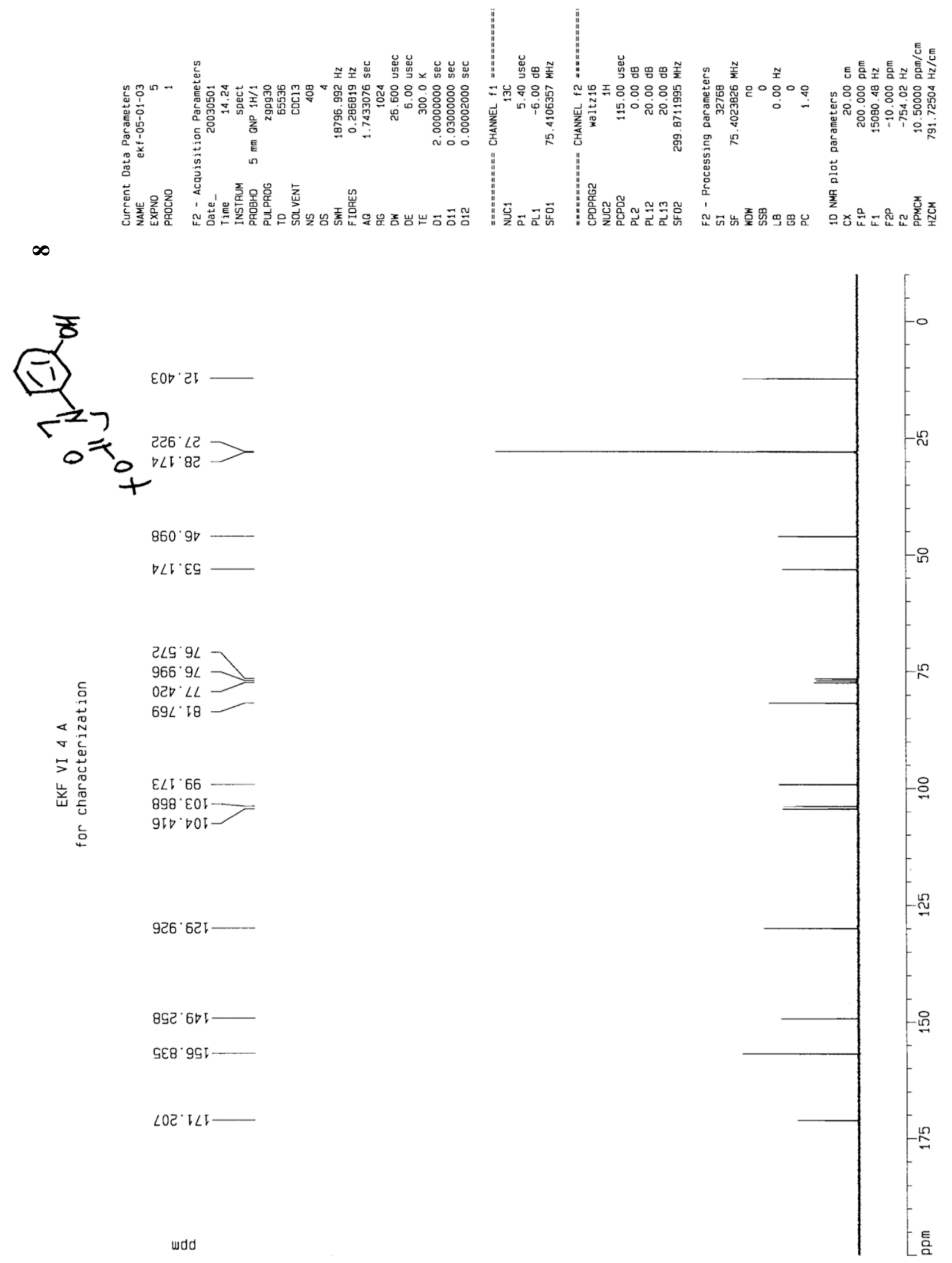




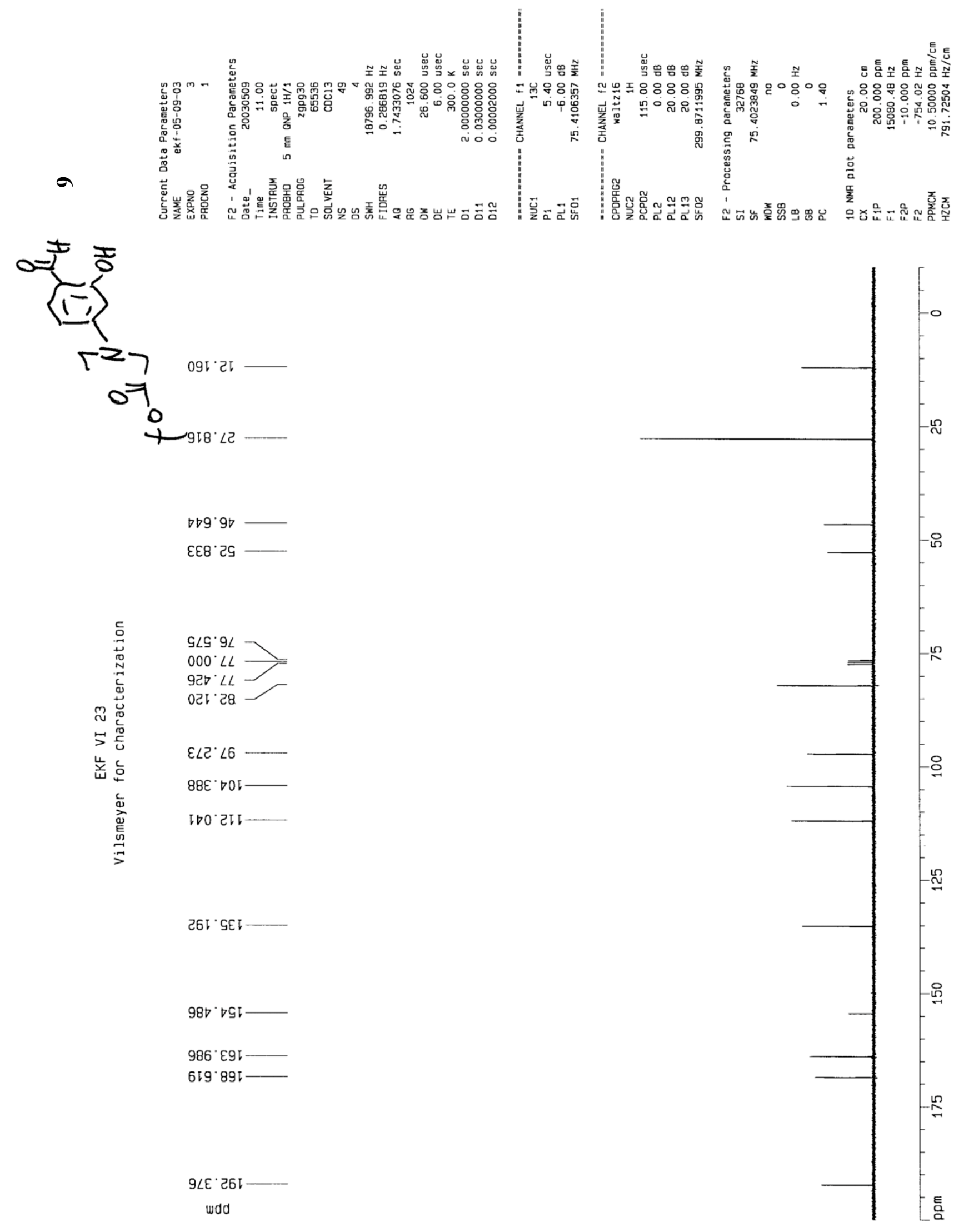




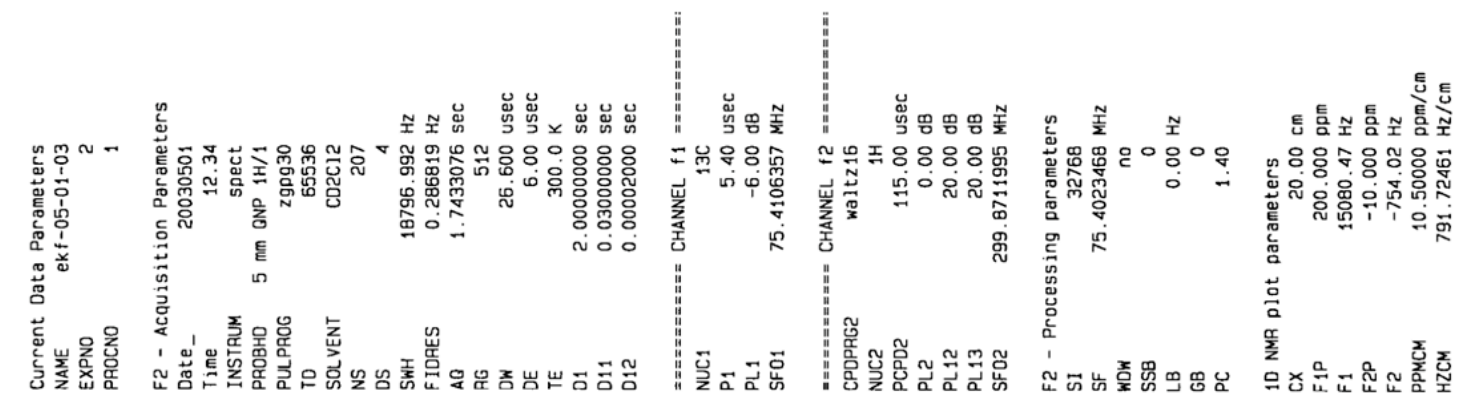

으

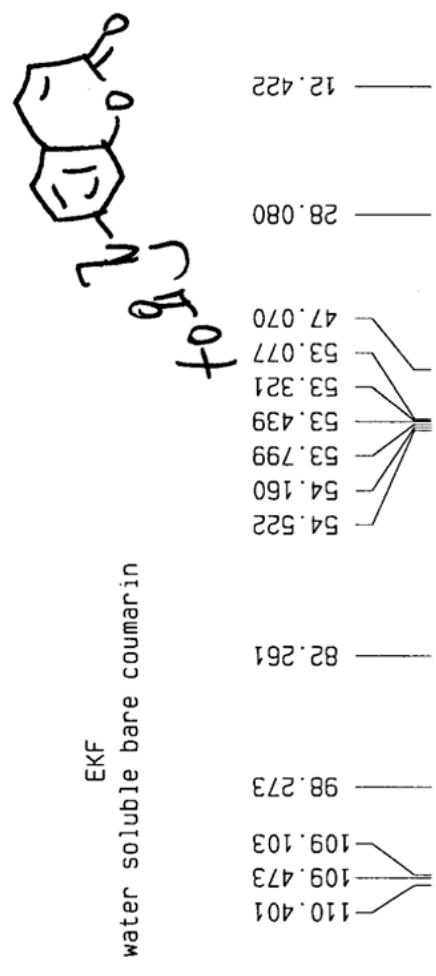

$190^{\circ} 625$

$298^{\circ} \varepsilon \nabla I-$

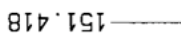

$\nabla 6 L^{\circ} 995$

006.91

Sจワ'69I-

wdd

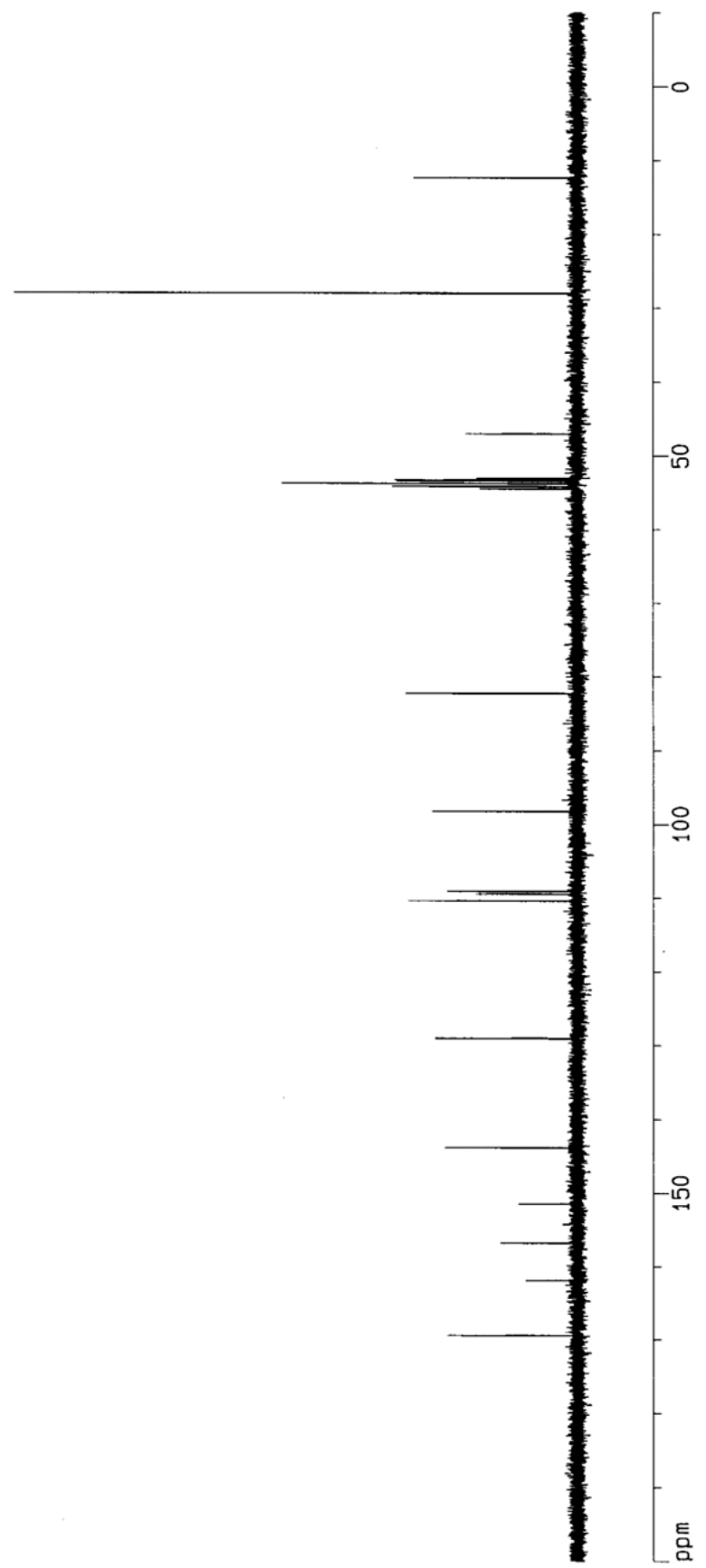



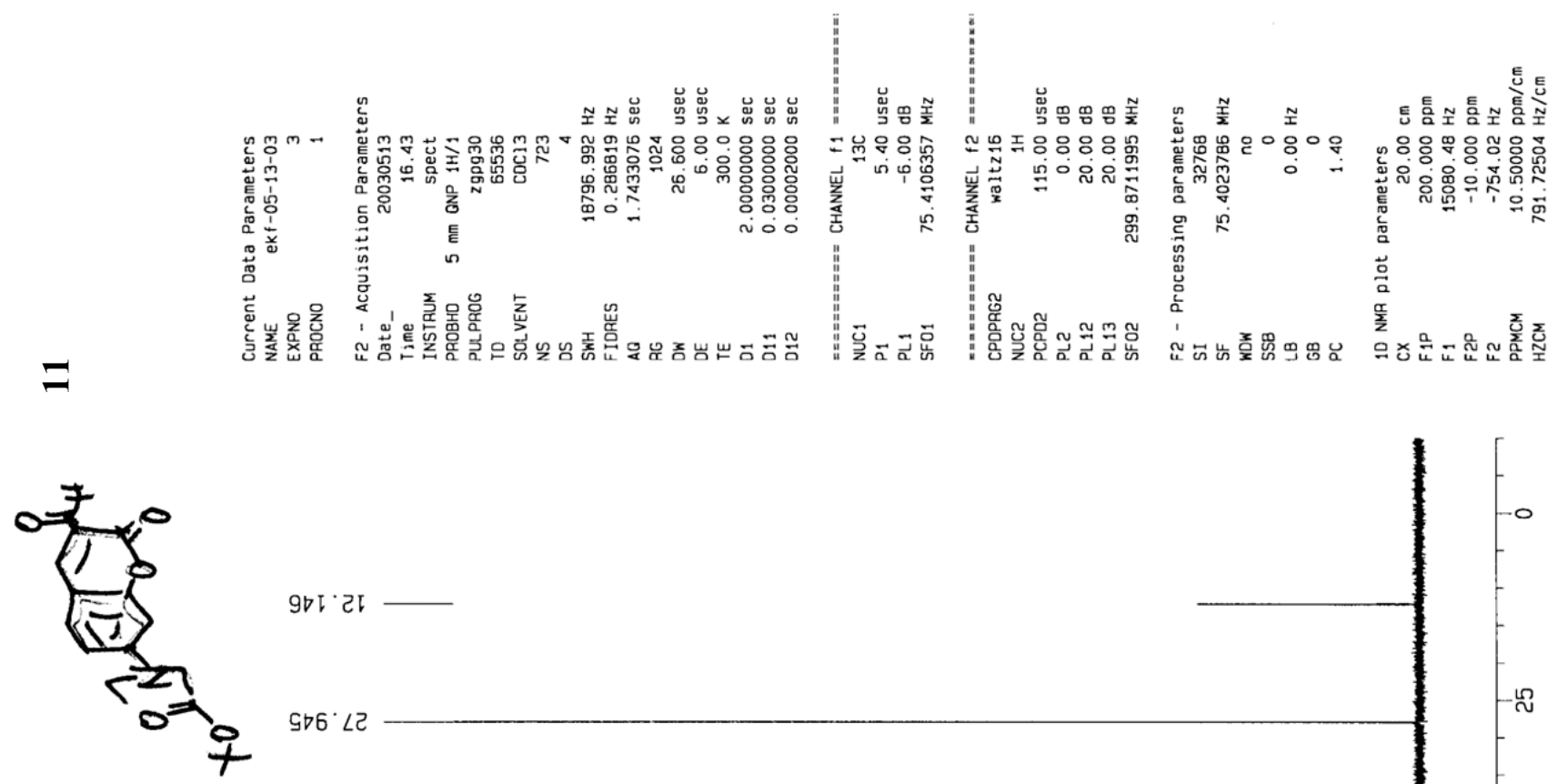

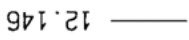

$9 \sqcup 6^{\circ} \angle 2$

(n)

$\subseteq 8 \sigma^{\circ} \angle \mathrm{V}$

Е80 Е $\varepsilon$

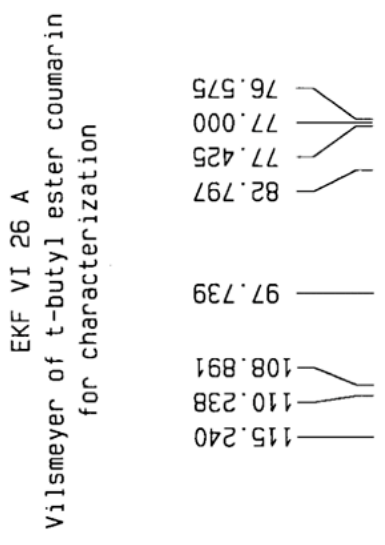

ОЕદ ટE - -

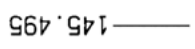

จટ८. દ૬โ- -

$8 \angle D^{\circ} 891-$

ट०I.89I-

L28' $\angle 81-$

wdd

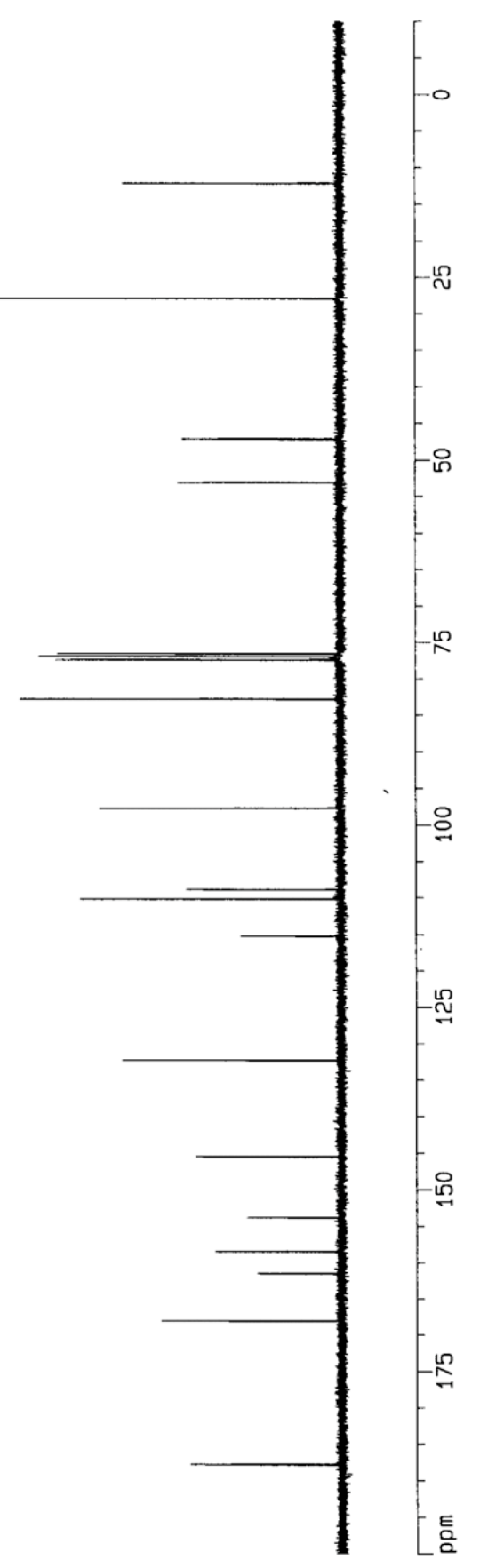




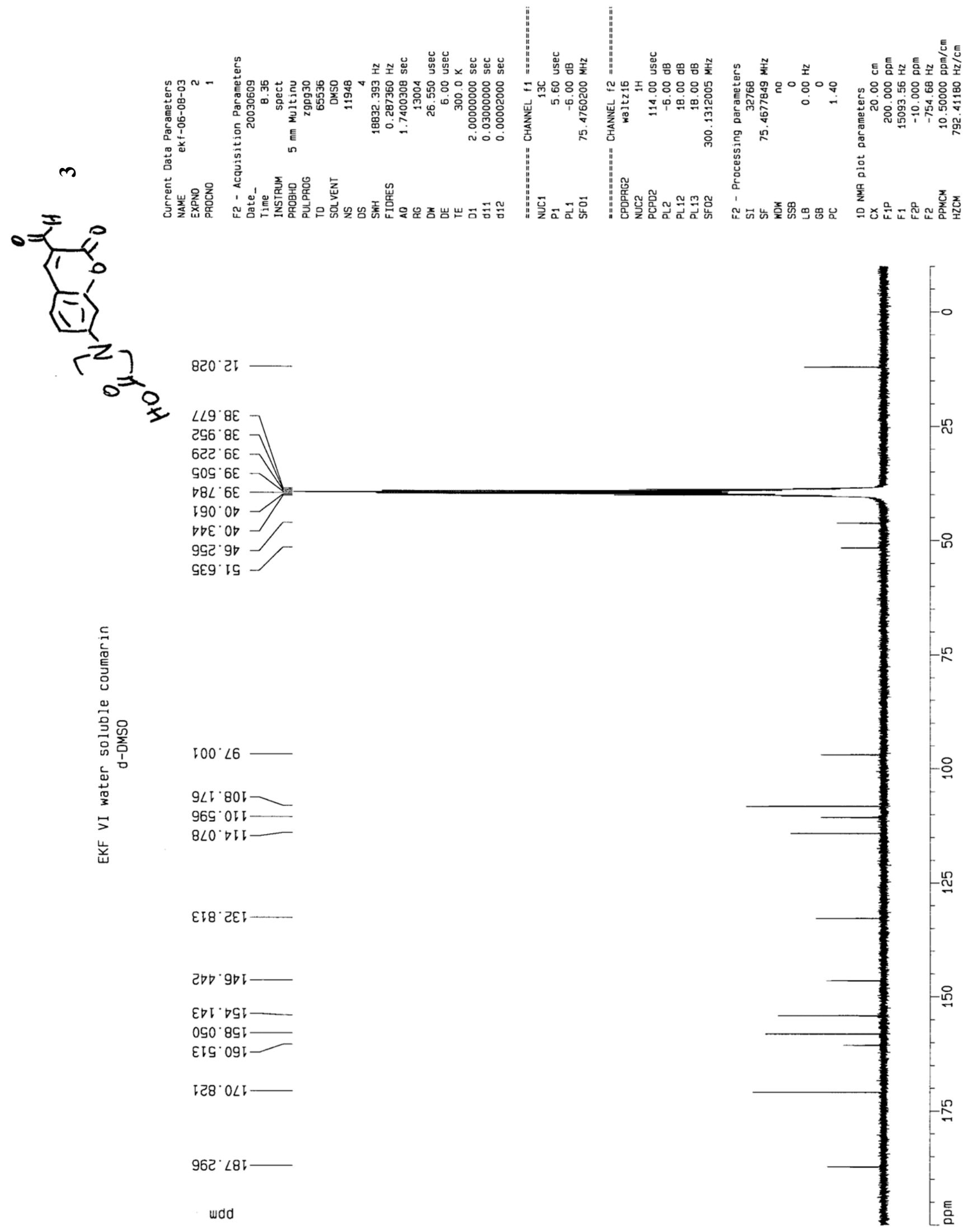

